\title{
Microelectronic Interconnection Bonding
With Ribbon Wire Interconnection Bonding
With Ribbon Wire
}

\section{PARTMENT}

U.S. OF COMMERCE

National Rureau QC 100 ds 5753

10.767 1973

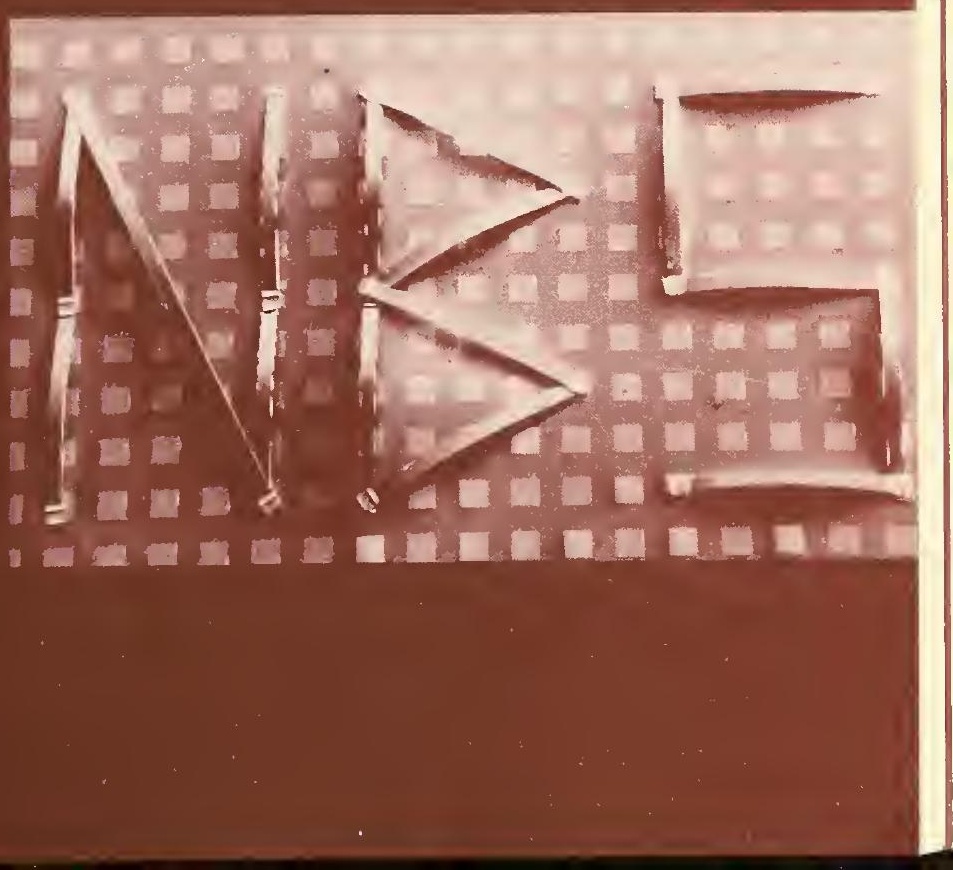




\section{NATIONAL BUREAU OF STANDARDS}

The National Bureau of Standards ${ }^{1}$ was established by an act of Congress March 3 , 1901. The Bureau's overall goal is to strengthen and advance the Nation's science and technology and facilitate their effective application for public benefit. To this end, the Bureau conducts research and provides: (1) a basis for the Nation's physical measurement system, (2) scientific and technological services for industry and government, (3) a technical basis for equity in trade, and (4) technical services to promote public safety. The Bureau consists of the Institute for Basic Standards, the Institute for Materials Research, the Institute for Applied Technology, the Center for Computer Sciences and Technology, and the Office for Information Programs.

THE INSTITUTE FOR BASIC STANDARDS provides the central basis within the United States of a complete and consistent system of physical measurement; coordinates that system with measurement systems of other nations; and furnishes essential services leading to accurate and uniform physical measurements throughout the Nation's scientific community, industry, and commerce. The Institute consists of a Center for Radiation Research, an Office of Measurement Services and the following divisions:

Applied Mathematics - Electricity - Mechanics - Heat - Optical Physics Linac Radiation ${ }^{2}$ - Nuclear Radiation ${ }^{2}$ - Applied Radiation ${ }^{2}$ - Quantum Electronics ${ }^{3}$ - Electromagnetics ${ }^{3}$ - Time and Frequency ${ }^{3}$ - Laboratory Astrophysics : - Cryogenics ${ }^{3}$.

THE INSTITUTE FOR MATERIALS RESEARCH conducts materials research leading to improved methods of measurement, standards, and data on the properties of well-characterized materials needed by industry, commerce, educational institutions, and Government; provides advisory and research services to other Government agencies; and develops, produces, and distributes standard reference materials. The Institute consists of the Office of Standard Reference Materials and the following divisions:

Analytical Chemistry-Polymers-Metallurgy-Inorganic Materials-Reactor Radiation-Physical Chemistry.

THE INSTITUTE FOR APPLIED TECHNOLOGY provides technical services to promote the use of available technology and to facilitate technological innovation in industry and Government; cooperates with public and private organizations leading to the development of technological standards (including mandatory safety standards), codes and methods of test; and provides technical advice and services to Government agencies upon request. The Institute also monitors NBS engineering standards activities and provides liaison between NBS and national and international engineering standards bodies. The Institute consists of a Center for Building Technology and the following divisions and offices:

Engineering and Product Standards-Weights and Measures-Invention and Innovation-Product Evaluation Technology-Electronic Technology-Technical Analysis-Measurement Engineering-Building Standards and Code Services $^{4}$ - Housing Technology ${ }^{4}$-Federal Building Technology ${ }^{4}$-Structures, Materials and Life Safety ${ }^{4}$-Building Environment ${ }^{*}$-Technical Evaluation and Application ${ }^{4}$-Fire Technology.

THE INSTITUTE FOR COMPUTER SCIENCES AND TECHNOLOGY conducts research and provides technical services designed to aid Government agencies in improving cost effectiveness in the conduct of their programs through the selection, acquisition, and effective utilization of automatic data processing equipment; and serves as the principal focus within the executive branch for the development of Federal standards for automatic data processing equipment, techniques, and computer languages. The Center consists of the following offices and divisions:

Information Processing Standards-Computer Information-Computer Services -Systems Development-Information Processing Technology.

THE OFFICE FOR INFORMATION PROGRAMS promotes optimum dissemination and accessibility of scientific information generated within NBS and other agencies of the Federal Government; promotes the development of the National Standard Reference Data System and a system of information analysis centers dealing with the broader aspects of the National Measurement System; provides appropriate services to ensure that the NBS staff has optimum accessibility to the scientific information of the world, and directs the public information activities of the Bureau. The Office consists of the following organizational units:

Office of Standard Reference Data-Office of Technical Information and Publications-Library-Office of International Relations.

\footnotetext{
1 Headquarters and Laboratorles at Galthersburg, Maryland, unless otherwise noted; malling address Washington, D.C. 20234

2 Part of the Center for Radlation Research.

a Located at Boulder, Colorado 80302 .

4 Part of the Center for Bullding 'l'echnology.
} 
H. K. Kessler and A. H. Sher

Electronic Technology Division

Institute for Applied Technology

National Bureau of Standards

Washington, D.C. 20234

This research was supported by the Advanced Research Projects Agency of the Department of Defense under ARPA ORDER 1889

M. Chernoff, ARPA Agent/Project Officer

Directorate of Technology/SYS

Space and Missile Systems Organization

Air Force Unit Post Office

Los Angeles, CA 90045

SAMSO MIPR FY 76167100331

NBS Technical Notes are designed to supplement the

Bureau's regular publications program. They provide a means for making available scientific data that are of transient or limited interest. Technical Notes may be listed or referred to in the open literature.

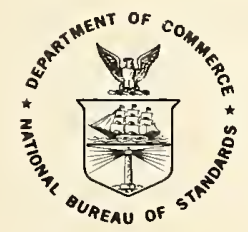

U.S. DEPARTMENT OF COMMERCE, Frederick B. Dent, Secretary

NATIONAL BUREAU OF STANDARDS, Richard W. Roberts, Director

Issued April 1973 


\section{National Bureau of Standards Technical Note 767}

Nat. Bur. Stand. (U.S.), Tech. Note 767, 31 pages (Apr. 1973)

CODEN: NBTNAE

Cover photograph. SEM photomicrograph of bonds made with 3 - by $0.5-$ mil aluminum ( $1 \%$ silicon) wire on 5 -mil square aluminum pads. The capability of placing ribbon-wire bonds one on top of another is shown. Four bonds are stacked at the center of the letter " $\mathrm{B}$ " (Magnification 60X)

For sale by the Superintendent of Documents, U.S. Goverument Printing Office, Washington, D.C. 20402 (Order by S1) Catalog No. Ci13.46:767).

Price $\$ 0.50$ domestic postpaid or $\$ 0.35$ G.P.O. Bookstore. 


\section{TABLE OF CONTENTS}

PAGE

Foreword . . . . . . . . . . . . . . . . . v1

1. Introduction . . . . . . . . . . . . . . . . 1

1.1. Units . . . . . . . . . . . . . . 2

2. Fabrication and Testing of Wire Bonds . . . . . . 2

2.1. Fabrication of Bonding Pads . . . . . . . . . 2

2.2. Procedures Used to Measure Bond Pull and Wire Tensile Strengths . . . . . . . . . . 3

3. Exploratory Studies . . . . . . . . . . . 3

3.1. Ribbon Wire Bonder . . . . . . . . . . . 3

3.2. Bonding Tools . . . . . . . . . . . . 4

3.3. Ribbon Wire .. . . . . . . . . . . 4

3.4. Hard Wire Bonds . . . . . . . . . . . . 5

3.5. Ribbon Wire Bonds - Initial Results . . . . . . 6

4. Results . . . . . . . . . . . . . 8

4.1. Comparison of Ribbon and Round Wire Pul1 Strength . . . . . . . . . . . . . 8

4.2. Pull Strength as a Function of Loop Height . . . . 13

4.3. Magnesium-Doped Wire . . . . . . . . . . 17

4.4. Gold Wire .. . . . . . . . . . . . 17

5. Bonding Equipment . . . . . . . . . . . 18

5.1. Wire Clamps .. . . . . . . . . . 18

5.2. Tools . . . . . . . . . . . . . 19

6. Conclusions . . . . . . . . . . . . 23

7. Acknowledgements . . . . . . . . . . . 23

8. References . . . . . . . . . . . . 23 


\section{LIST OF F I GURES}

PAGE

SEM photomicrograph of bonds made with 3- by

0.5 -mil aluminum ( $1 \%$ silicon) wire . . . . . . . cover

1. SEM photomicrograph of a rectangular wire-feed

hole in an ultrasonic bonding tool . . . . . . . 5

2. SEM photomicrograph of a ribbon wire first bond

made with low power and long time . . . . . . . . 7

3. SEM photomicrograph of a ribbon wire first

bond made with high power and relatively short

time ................... . 7

4. SEM photomicrograph of three bonds made with

aluminum ribbon wire on a bonding pad 5-mils

square .......................

5. SEM photomicrograph of three stacked bonds made with aluminum ribbon wire . . . . . . . . .

6. Pull strength of ribbon wire bonds as a function of time and tool tip displacement . . . . . . . .

7. Pull strength of round wire bonds as a function of time and tool tip displacement . . . . . . . . .

8. Pull strength of ribbon wire bonds as a function of time and tool tip displacement; bonding force of $35 \mathrm{gf}$. . . . . . . . . . . . . .

9. Time and tool tip displacement settings that yield bonds with a pull strength of $7 \mathrm{gf}$ or greater.

10. Time and tool tip displacement settings that yield bonds with a pull strength of $10 \mathrm{gf}$ or greater . . . . . . . . . . . . . . . .

11. Pull strength of ribbon wire bonds as a function of loop height

12. SEM photomicrograph of two views of a bonding tool showing rough surface finish 
13. SEM photomicrograph of two views of a bonding

tool with a relatively smooth surface finish . . . 20

14. SEM photomicrograph of two views of a bonding tool showing pin holes in the surface finish . . . . 21

15. SEM photomicrograph of two views of a tungsten carbide bonding tool showing build-up of gold at the wire-feed hole . . . . . . . . . 21

\section{LIST OF TABLES}

1. Specifications of Wire Studied . . . . . . . . . 5

2. Comparison of Pull Strengths of Ribbon and Round Wire Bonds . . . . . . . . . . . . . 


\section{FOREWORD}

This technical note is the final report to the Advanced Research Projects Agency for the period June 1, 1971 to May 31, 1972 on a study designed to show the feasibility of using aluminum ribbon wire for ultrasonic bonding of semiconductor microelectronic device interconnections. The work was carried out under contract number MIPR FY 76167100331 (ARPA Order Number 1889), M. Chernoff ARPA Agent/Project Officer. 
MICROELECTRONIC INTERCONNECTION BONDING

WITH RIBBON WIRE

\author{
H. K. Kessler and A. H. Sher \\ Electronic Technology Division \\ Institute for Applied Technology \\ National Bureau of Standards \\ Washington, D.C. 20234
}

The feasibility of using aluminum ribbon wire for ultrasonic bonding of semiconductor microelectronic interconnections was studied, and several advantages over the use of round wire of equivalent cross-sectional area were found. Ribbon wire bonds exhibited little deformation or heel damage, and a greater percentage of bonds of a certain quality (as judged by pull strength and appearance) could be made over much greater ranges of the bonding machine parameters, time and tool tip displacement, using ribbon wire than was possible with round wire. The ease of positioning ribbon wire was indicated by making multiple ribbon wire bonds side-by-

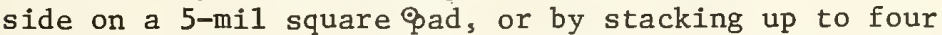
bonds one on top of another. However, bonding with harder than normal wire, previously thought to offer certain advantages with respect to higher bond tensile strength, yielded inconsistent results.

Key Words: Aluminum wire; bonding; fabrication (wire bonds); microelectronics; ribbon wire; round wire; testing (wire bond); ultrasonic bonding; wire bond.

\title{
1. INTRODUCTION
}

At the start of this study, there was no reported industrial use of aluminum ribbon wire for microelectronic ultrasonic bonding nor were ribbon wire bonding machines and suitable aluminum ribbon wire generally available. Prior exploratory work at NBS had indicated that the use of 
ribbon wire offered significant advantages over the conventionally used round wire $[1,2]$. The present study was undertaken in order to investigate the use of aluminum ribbon wire for ultrasonic bonding in semiconductor microelectronics, with emphasis on the advantages over round wire and the problems that might be encountered in converting presently used round wire bonding equipment to ribbon wire use.

The criteria used in evaluating bond quality were, primarily, pull strength and, secondarily, appearance. The pull strength was measured using a double bond, destructive pull test. The appearance criterion was based upon a subjective evaluation of the surface finish of the resulting bond and the degree of deformation at the heel as observed under high magnification, usually with a scanning electron microscope (SEM).

\subsection{Units}

The following units which are in general usage in the bonding field are used rather than the International System (SI) of units in this report: ( 1 ) mils $(1 \mathrm{mil}=25.4 \mu \mathrm{m}$ ) for dimensions of the wire, bond loop, bond spacing, substrate, and tool, and (2) grams-force ( $1 \mathrm{gf}=9.8 \mathrm{mN}$ ) for the force exerted on the wire or wire bond.

\section{FABRICATION AND TESTING OF WIRE BONDS}

Except where otherwise noted, wire bonds studied in the present work were fabricated on a commercial ultrasonic wire bonder equipped with a tungsten carbide tool. This bonder, which had been modified to improve its mechanical stability and temperature characteristics [3], was further modified to facilitate the use of ribbon wire. Some exploratory studies were performed using bonds made on a different bonder, one that was intended for ribbon-wire use but later found not to give optimum results. Unless otherwise specified, the nominal value of bond loop height was $10 \mathrm{mils}$, bond-to-bond spacing was $40 \mathrm{mils}$, and bonding force was $25 \mathrm{gf}$.

\subsection{Fabrication of Bonding Pads}

Bonding pads were fabricated on 10-mil thick, 1-inch diameter silicon wafers coated with a 0.8 - to $1.0-\mu \mathrm{m}$ thick film of steam-grown 


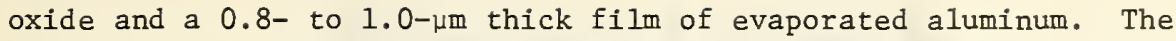
aluminum was etched to leave 5-mil square bonding pads on 10-mil centers by means of standard photolithographic techniques. After etching, the array of square bonding pads was sintered in a helium atmosphere at $550^{\circ} \mathrm{C}$ for 15 min. Such an array is shown in the cover photograph.

2.2. Procedures Used to Measure Bond Pull and Wire Tensile Strengths In all of the measurements reported here, the pulling force was applied normal to the plane of the single-level substrates. Pulling was accomplished with an electrolytically-etched wire hook driven by a switch-controlled adjustable speed motor at a pull rate of $1 \mathrm{gf} / \mathrm{s}$. The hook was mounted on a micropositioner so that it could be precisely aligned with respect to the wire. The pulling force was measured by a gram-gage dynamometer.

The wire was prepared for measurement of tensile strength by affixing one end of a 10- to 15-mm length of wire to a base plate with room-temperature curing epoxy and placing a ball of the epoxy on the other end. A small fork placed under the epoxy ball was used to apply the test force. Using the pulling apparatus, each of ten wire specimens was pulled to breaking and the results averaged. Only specimens that exhibited a break in the wire were counted in calculating the average.

\section{EXPLORATORY STUDIES}

\subsection{Ribbon Wire Bonder}

Initial efforts to achieve optimum performance and reliability with a bonder manufactured for use with ribbon wire were hampered by a vertical jumping motion of the bonding tool after the first bond had been made. This tended to cause severe cracking in the bond heel. Considerable reduction of the undesired motion was achieved by regrinding the appropriate cam surfaces by hand.

Another problem with the bonder was a considerable variability of bond tail-length that it would produce. This was reduced by a factor of two by improving the wire-feed mechanism. This tail-length variation, which is of only cosmetic concern to bonding on a laboratory basis, must be controlled before the machine can be used in production since long 
wire tails in actual devices may cause short circuits.

\subsection{Bonding Tools}

A feature of the bonding tool that was considered desirable but not essential for the initial studies was a rectangular wire-feed hole. At the time these studies were to begin, commercial tools with rectangular feed holes could not be located. However, one company agreed to make such tools if supplied with tungsten wire of rectangular cross section required for the electrical-discharge-machining operation to fabricate such holes. A simple procedure was developed to form the tungsten ribbon wire. Lengths of $1-\mathrm{mil}$ and 2-mil diameter round wire were flattened by placing the tungsten wire in a press between glass plates and applying a load to 45 to $76 \mathrm{MN} / \mathrm{m}^{2}$ for 1 -mil diameter wire, or 103 to $145 \mathrm{MN} / \mathrm{m}^{2}$ for 2-mil diameter wire. The resulting ribbon was not generally uniform, but pieces could be selected for the desired sizes of rectangular holes.

At a later time, a supplier of tools with rectangular feed holes was located. An SEM photomicrograph of the rectangular feed hole in one of the commercially-available tools is shown in figure 1.

\subsection{Ribbon Wire}

The aluminum ribbon wire used for most of the experimental work was doped with one percent silicon and had cross-sectional dimensions of 1.5 by 0.5 mils. This results in about the same cross-sectional area for the ribbon wire as for 1-mil diameter round wire. Aluminum wire doped with one percent magnesium, silicon-doped aluminum wire of larger dimensions, and undoped gold wire were also studied. Table 1 lists the composition, tensile strength, and nominal cross-sectional dimensions for the various ribbon wire used.

The desired variation of the cross-sectional dimensions was equal to or less than 10 percent. Difficulty was encountered in obtaining wire with this degree of control. Contacts with three manufacturers of ultrasonic bonding wire were required, and nearly half of the period for this study passed, before satisfactory wire was obtained.

The ribbon wire was obtained on 0.5-in. or 2-in. diameter spools. Wire wound on the 2-in. spools showed less twisting and binding and 


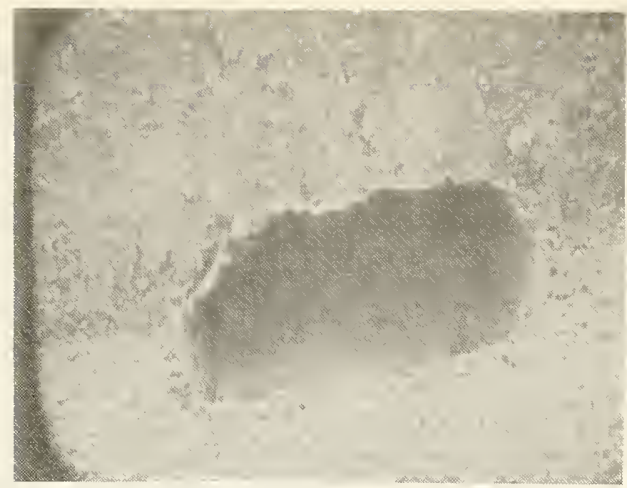

Figure 1: SEM photomicrograph of a rectangular wire-feed hole in an ultrasonic bonding tool. (There is a slight build up of aluminum in the upper left corner of the hole. Magnification: about 750x.)

Table 1: Specifications of Wire Studied

Lot Composition

\section{Dimensions} (mils)

A Al ( $1 \% \mathrm{Si})$

B $\mathrm{AI}(1 \% \mathrm{Mg})$

C $\mathrm{AI}(1 \% \mathrm{Mg})$

D $\mathrm{Au}$

E
$1.5 \times 0.5$

$1.5 \times 0.5$

$1.5 \times 0.5$

$1.5 \times 0.8$

AI ( $1 \% \mathrm{Si})$
1.0 (dia.)
Tensile Strength

Range (gf)

$$
13.0-13.5 a
$$$$
\text { 214 }
$$$$
23.1-23.5^{\mathrm{a}}
$$

ح15

$12.5-13.2^{\mathrm{a}}$

Comments

partially annealed ${ }^{b}$ partially annealed hard wire partially annealed partially annealed

a

low and high values of breaking strength as measured in the laboratory (see text)

b

by manufacturer

exhibited better feeding characteristics through the transducer horn, wire clamp, and bonding tool. The tail length and loop height were also more uniform in bonds made from wire wound on the larger spools. Only minor modification of the bonders was needed to accommodate the larger spools.

3.4. Hard-Wire Bonds

It had been speculated [1] that high tensile strength ("hard") ribbon wire could be used to achieve considerably higher bond strengths 
than with round wire. The expectation was that significant damage to the substrate would not occur with the higher ultrasonic power and bonding force required when using hard wire because less deformation of the ribbon wire occurred. However, in a preliminary test bonding with hard wire (Lot $C$ ) proved to be very difficult, and inconsistent results were obtained. The power range in which bonds of high pull strength could be obtained was narrow, and the other bonding parameters were critical in order to accomplish a low variability in mean pull strength. On lifted bonds (those carefully peeled from the substrate), cratering was observed in the substrate due to the increased bonding force required to obtain adherent bonds. Though this experiment was performed using magnesiumdoped wire, no significant difference would be expected using silicondoped wire (see Section 4.3.). Because of the high quality of bonds later found with stress-relieved wire, no further attempts to bond with hard wire were made during subsequent phases of the work.

\subsection{Ribbon Wire Bonds - Initial Results}

About 2000 bonds were made with Lot A wire on several single-level bonding substrates in order to investigate the pull strength and appearance of bonds made with different bonding power and time. The bond-tobond spacing was 40 mils, similar to that used in typical devices. A single tool was used to make all the bonds.

A better appearance was obtained with low ultrasonic power and relatively long bonding time (figure 2) than with the higher ultrasonic power and shorter bonding time usually employed in round-wire bonding. In the latter case, the bond surface appearance was rough and irregular, and a significant heel crack appeared in the first bond (figure 3 ). The bond shown in figure 2, typical of those made with the low-power, long time schedule, had a pull strength approximately 1.5 times that of the bond shown in figure 3, typical of those made with the high-power, short-time schedule.

A test was conducted to establish that the positioning and deformation of the bonded ribbon wire could be controlled sufficiently to permit the use of the same size bonding pad that would be required for round wire of cross-sectional area equivalent to the ribbon wire. 


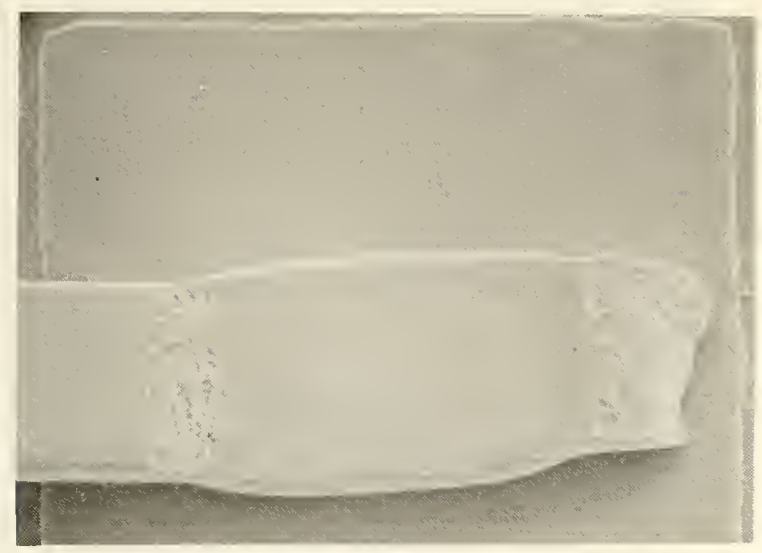

Figure 2: SEM photomicrograph of a ribbon wire first bond made with low power [20- $\mu$ in. $(0.5-\mu \mathrm{m})$ peak-to-peak tip amplitude] and long time [155 ms] (Magnification 470X).

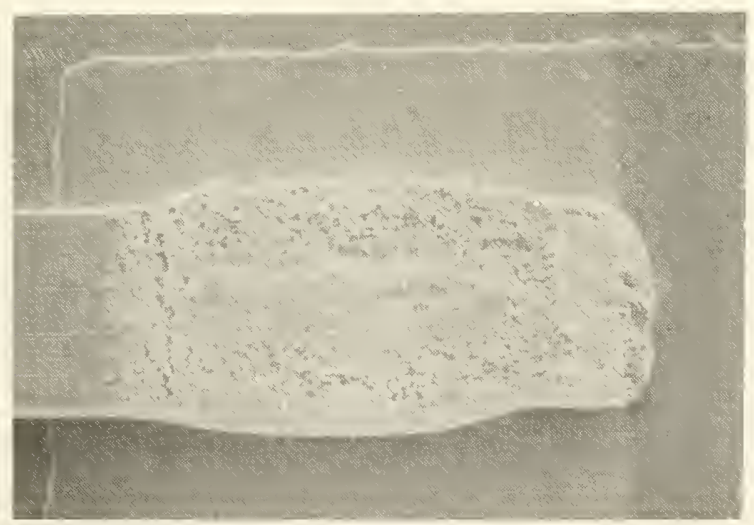

Figure 3: SEM photomicrograph of a ribbon wire first bond made with high power [82- $\mu$ in. (2.1- $\mu \mathrm{m})$ peak-to-peak tool tip amplitude] and relatively short time [40 ms] (Magnification $\sim 500 \mathrm{X}$ ). 
Three bonds were made with 1.5 - by $0.5-$ mil aluminum ( $1 \%$ silicon) ribbon wire side-by-side on a bonding pad 5 mils square. The result, pictured in figure 4, dispelled any concern that larger bonding pads may be required if ribbon wire is used. Figure 5 shows that ribbon wire bonds can be stacked directly one on top of another. This, along with the cover photograph, further illustrates the degree of control in bond placement that the use of ribbon wire offers. This can be an important consideration in device repair or replacement, especially for hybrid devices, and for high frequency devices in which lead inductance must be minimized.

\section{RESULTS}

Measurements were carried out using aluminum ( $1 \%$ silicon) wire: (1) to compare directly the pull strengths of ribbon and round wire with equivalent cross-sectional areas, (2) to determine the bonding parameters (time, bonding force, and tool tip displacement) necessary to obtain optimum bonds, and (3) to examine the effects of changes in the bonding parameters on bond appearance and deformation. The results of these measurements are given below. Results of bond pull strength measurements using aluminum (1\% magnesium) ribbon wire and gold ribbon wire ultrasonically bonded to aluminum pads are also reported.

\subsection{Comparison of Ribbon and Round Wire Pull Strengths}

Because the exploratory studies showed that high quality bonds could be made with ribbon wire, the investigation was broadened to compare ribbon and round wire bonds over a wide range of power and time settings for a constant bonding force of $25 \mathrm{gf}$. Using the same bonding machine and too ${ }^{*}$, wire bonds of both types (wire Lots A and E) were made with bond-to-bond spacings of $40 \mathrm{mils}$ and loop heights of 10 mils side-by-side on the same metallized silicon substrate in order to minimize any influence of differences in bonding conditions or substrate characteristics.

The use of the same tool (with round feed hole) for both round and ribbon wire results in less than optimum conditions for bonding ribbon wire (see Section 5.2.). 


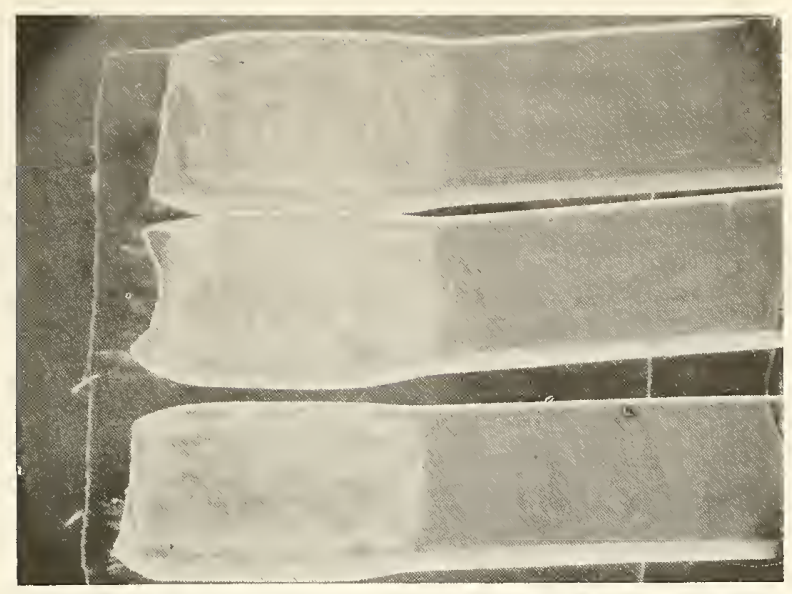

Figure 4: SEM photomicrograph of three bonds made with aluminum ribbon wire with cross-sectional dimensions 1.5 by $0.5 \mathrm{mils}$ on a bonding pad 5 -mils square. (The bonding schedule was low power [32- $\mu$ in. $(0.8-\mu \mathrm{m})$ peakto-peak tool tip amplitude] and medium time [80 ms]. Magnification 460X).

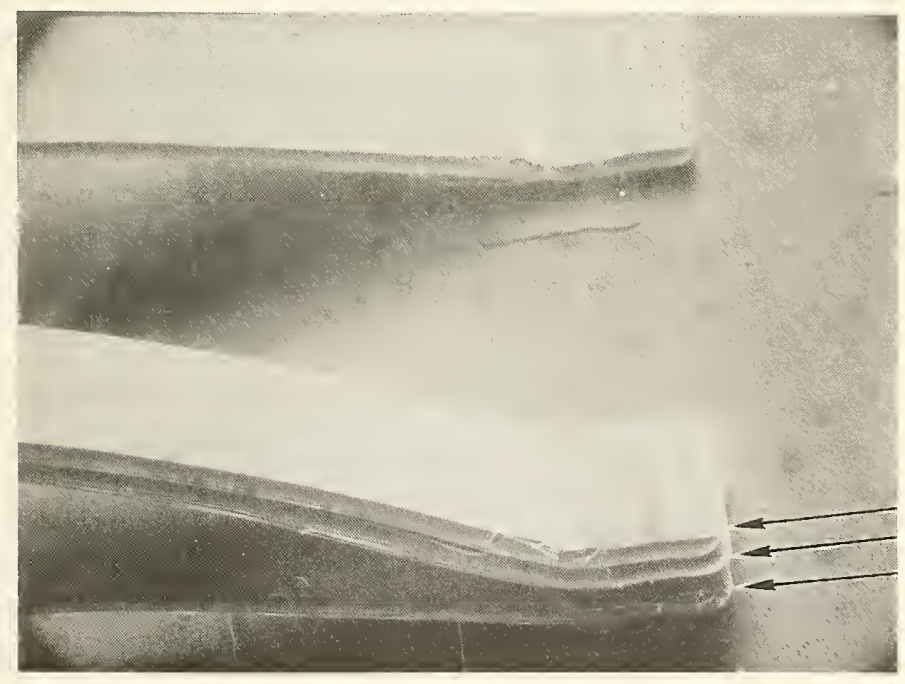

Figure 5: SEM photomicrograph of three stacked bonds (shown by arrows) made with aluminum ribbon wire with cross-sectional dimensions 3 by 0.5 mils on a $5-\mathrm{mil}$ square bonding pad (Magnification $200 \mathrm{X}$ ) 
For each combination of displacement and time, 10 bonds were made and their pull strengths determined by pulling vertically at the midpoint of the loop. The average pull strength for each group is plotted against both time and tip displacement in figures 6 and 7 for ribbon and round wire bonds, respectively. The data points have been connected by straight lines to define planes each of which includes groups of bonds made at a constant time but with a range of power (tool tip displacement). For convenience, different symbols are used for groups with mean pull strength less than 7, 7 to 10, and greater than $10 \mathrm{gf}$. For clarity the variance is not indicated in the figures. Open points and short dashed lines indicate portions of a plane lying behind another. In general, at the lower displacements, the major mode of the bond failure was bond lift off while at higher power it was breakage at the heel of the bond.

The results of a statistical analysis of the bond data considered as a whole are summarized.in table 2. The entries in this table are the averages of the mean pull strength of bond groups with mean pull strength in the specified range and the pooled sample standard deviation for the means. The number of groups included in each category is also given. The mean pull strength of bonds made using ribbon wire was a statistically significant eight percent higher than the mean pull strength of bonds made with round wire in the range of pull strengths greater than $10 \mathrm{gf}$. About 90 percent of the ribbon-wire bonds showed pull strengths greater than $7 \mathrm{gf}$ while only 42 percent of the round-wire bonds did for the power and time settings studied.

Also shown in table 2 are the results from a comparable series of ribbon-wire bonds using Lot $A$ wire made on a different substrate using a bonding force of $35 \mathrm{gf}$. Figure 8 shows plots of these data in a form similar to that of figures 6 and 7. In terms of the bond pull strength, the use of higher force appears to result in more of the bonds having pull strengths greater than $10 \mathrm{gf}$. However, microscopic examination of the substrate used for the series with higher bonding force after removal of the bonds and metallization indicated a slight amount of damage beneath the metallization. Such damage was not observed in the substrate used for the series with the lower force. 


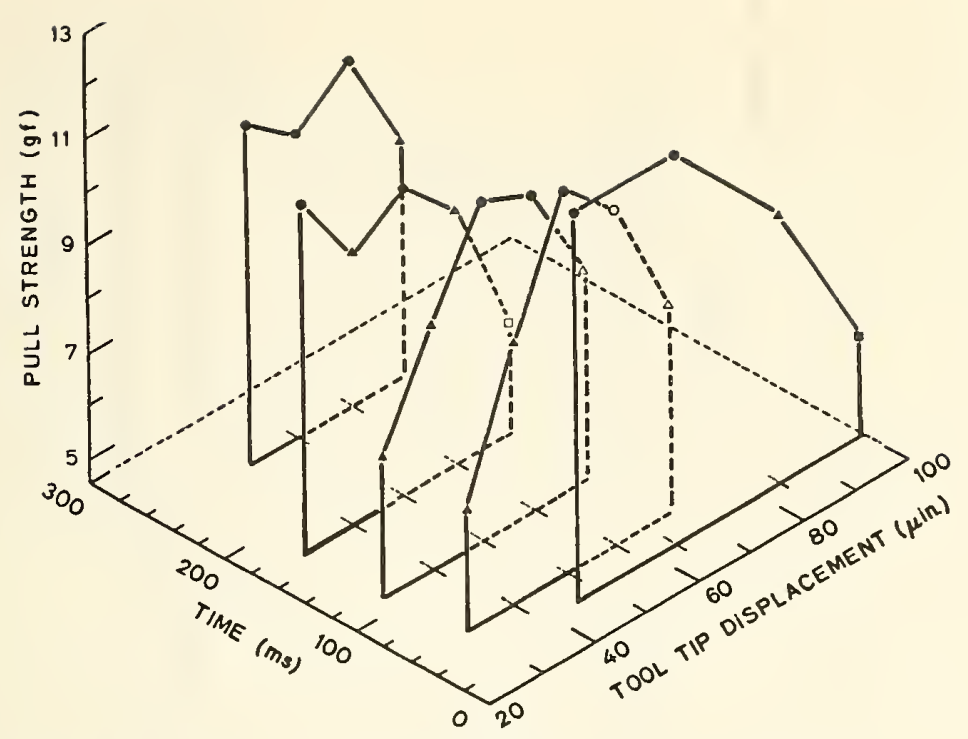

Figure 6: Pul1 strength of ribbon wire bonds as a function of time and tool tip displacement. (Bond pull strength range is shown by symbols: $0,0>10 \mathrm{gf}$; $\Delta, \Delta$ 7-10 $\mathrm{gf}$; and $\square, \square<7 \mathrm{gf}$.)

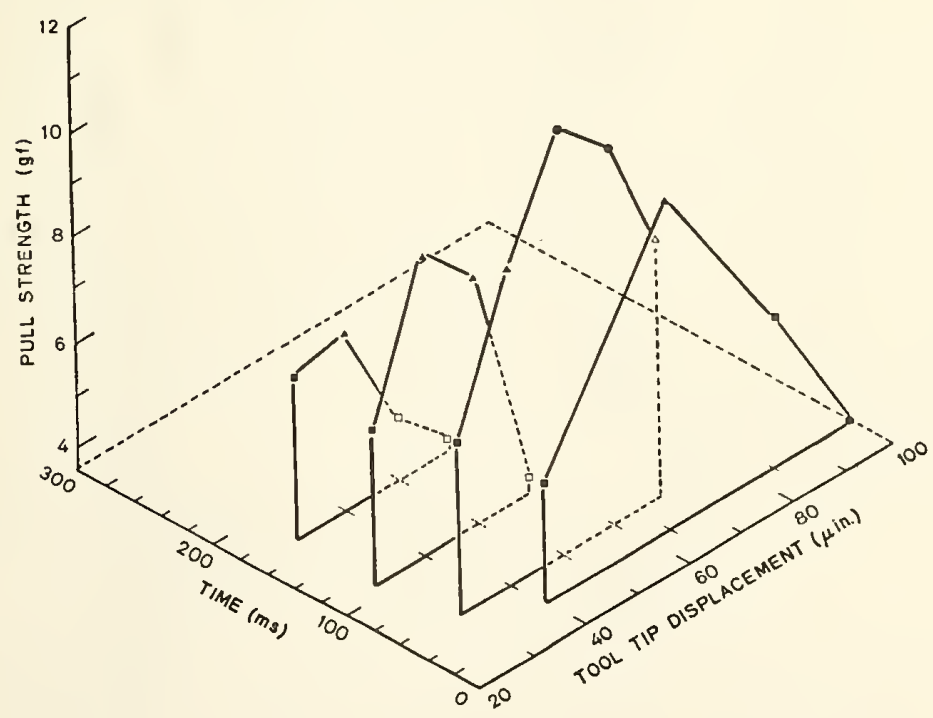

Figure 7: Pull strength of round wire bonds as a function of time and tool tip displacement. (Bond pull strength range is shown as in figure 6.) 


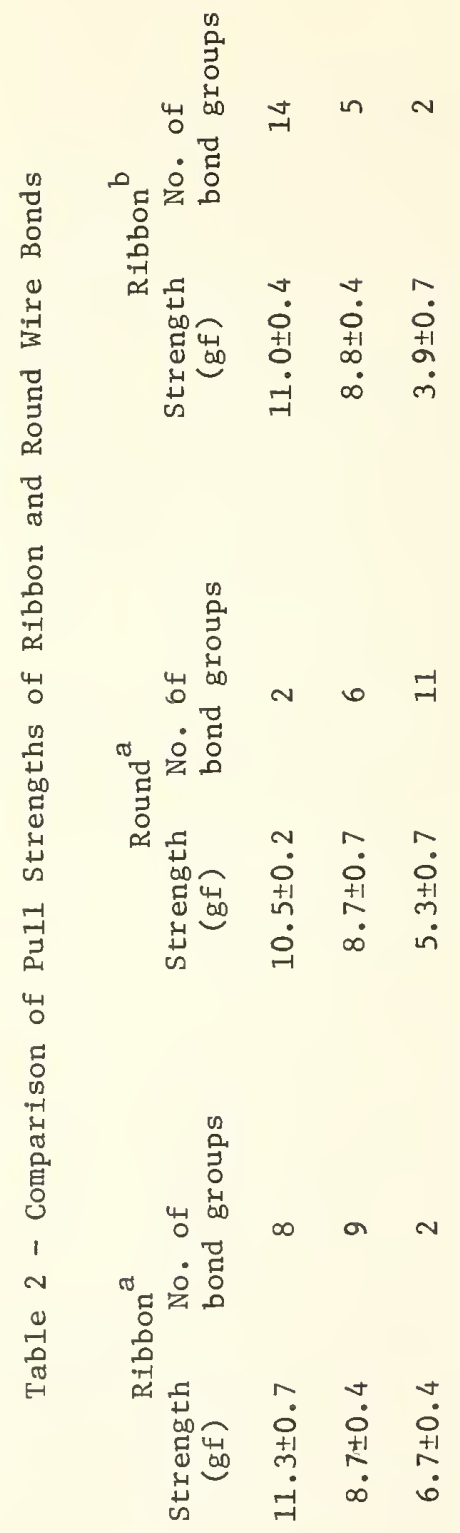

40

in 4

फ m

U

넌

on

갈

응 둥

(ง)

대

3 단

+) 3

齐

i)

눈

吾

ज

芩

苯

峁

塄

잉

ن

离

. 다

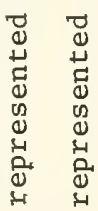

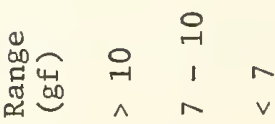

营 


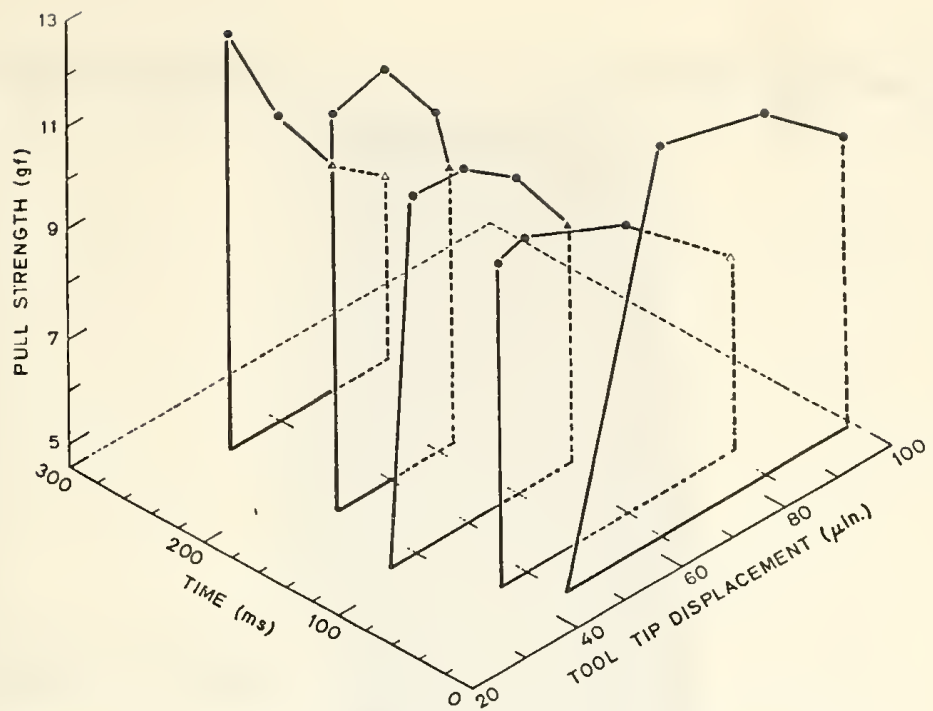

Figure 8: Pull strength of ribbon wire bonds as a function of time and tool tip displacement; bonding force of $35 \mathrm{gf}$. (Bond pull strength range is shown as in figure 6.)

The experiments reported above show that a major advantage of using ribbon over round wire is that with ribbon wire less precise control of bonding machine parameters is required to yield bonds of a certain quality than is required with round wire. This is illustrated graphically in figures 9 and 10 which delineate the regions of time and tool tip displacement where bonds of pull strength greater than 7 gf and $10 \mathrm{gf}$, respectively, were obtained. In both cases, these regions are much smaller for the round wire bonds than for the ribbon wire bonds. Although ribbon wire bonds with high pull strength were obtained over a much wider range of power and time than was indicated in the initial experiments, observations confirmed that, as previously reported, the best appearance was obtained at low power and long time.

\subsection{Pul1 Strength as a Function of Loop Height}

Measurements of ribbon wire bond pull strengths as a function of bond loop height were made. As shown in figure 11, up to a loop, height of about $10 \mathrm{mils}$, the variation of pull strength as a function of loop height is in good agreement with the mechanical resolution of forces analysis (solid curve) [4]. Above $10 \mathrm{mils,}$ the measured pull strength 


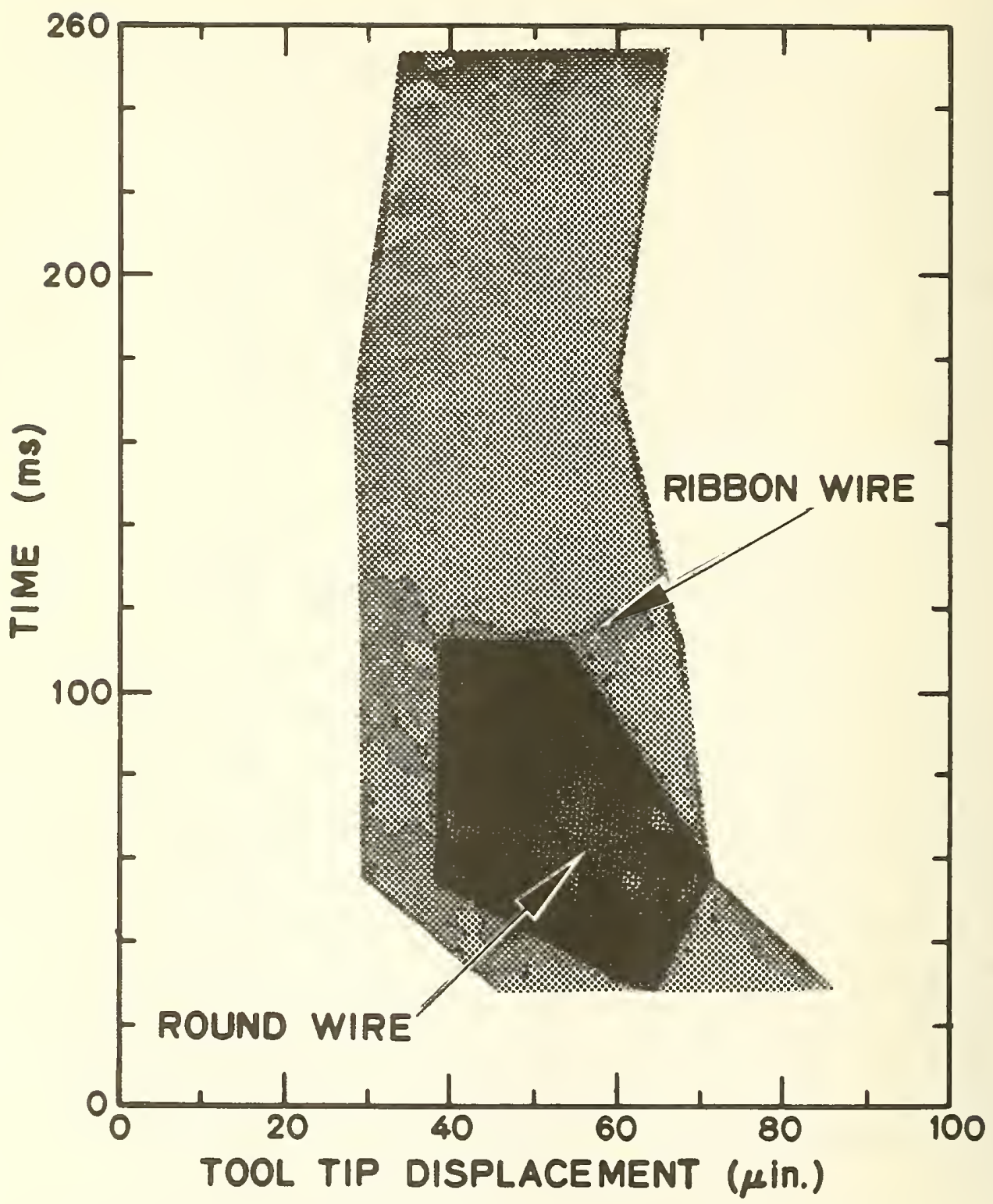

Figure 9: Time and tool tip displacement settings used in this work that yield bonds with a pull strength of $7 \mathrm{gf}$ or greater. 


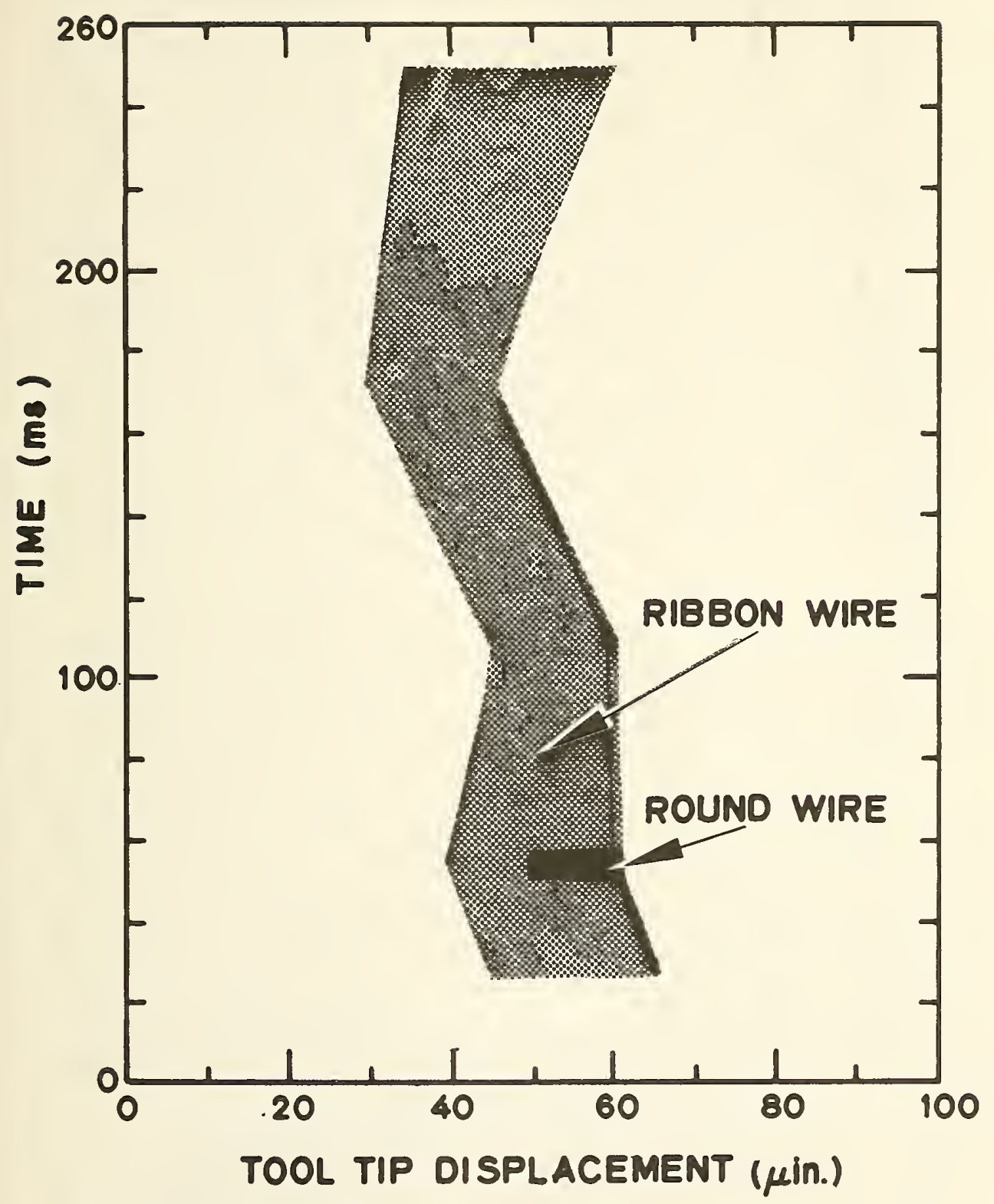

Figure 10: Time and tool tip displacement settings used in this work that yield bonds with a pull strength of $10 \mathrm{gf}$ or greater. 


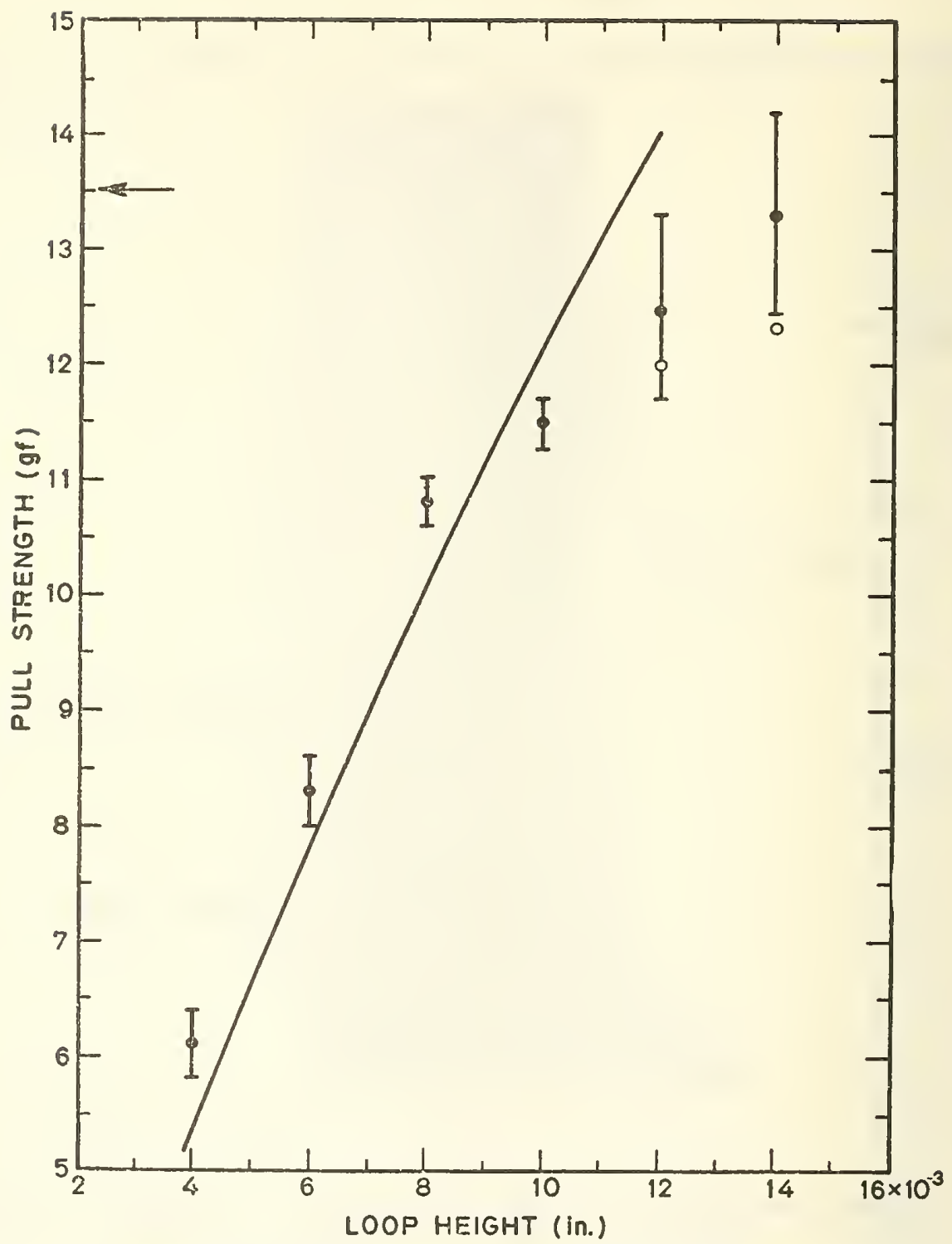

Figure 11: Pull strength of ribbon wire bonds as a function of loop height. (The data points represent the mean for up to 10 bonds. Solid circles include only bonds which ruptured at the heel; open circles include both bonds which ruptured at the heel and which failed by lift off. Error bars represent one sample standard deviation. The solid curve is calculated from resolution-of-forces using the wire tensile strength indicated by the arrow.) 
is lower than the predicted value. The solid data points are average pull strengths for groups of nominally 10 bonds each, excluding those bonds that failed due to lift off of one of the bond pairs. The error bars represent one sample standard deviation above and below the mean. To obtain the two open data points at the two highest loop heights used, pull strengths of bonds which failed by lift off were included in the average pull strength calculation. As the loop height becomes increasingly higher, more vertical pulling force is exerted on the bonds. The experimental data, where bond failure known to be due to complete lift off is included, suggest some peeling of the bond before breakage at the heel caused by the increased vertical pulling force might account for the measured pull strength being less than predicted. This conclusion is in agreement with the results of measurements of pull strength of round wire bonds as a function of loop height [5].

\subsection{Magnesium-Doped Wire}

The pull strength and appearance of bonds made with Lot $B$ aluminum (1\% magnesium) ribbon wire were investigated using single-level bonding substrates. A single tool with a round feed hole was used for all bonds.

Measurements of pull strength of bonds made with various values of ultrasonic power (tool tip displacement) and time showed that, in agreement with the results obtained on aluminum ( $1 \%$ silicon) ribbon wire, the use of a low-power, long-time bonding schedule resulted in higher pull strengths and better appearance than a high-power, short-time bonding schedule. The highest average pull strengths and smallest variations are obtained at tool tip vibration amplitudes of 25 to $35 \mu i n$. ( 0.6 to $0.9 \mu \mathrm{m}$ ) and times of 110 to $285 \mathrm{~ms}$. These groups of bonds made at low power and long time show mean pull strengths of from 11.0 to $12.2 \mathrm{gf}$ with an average standard deviation of \pm 4 percent about the mean. Thus, there appears to be no significant differences between aluminum (1\% magnesium) and aluminum ( $1 \%$ silicon) ribbon wire of comparable tensile strength.

\subsection{Gold Wire}

A series of experiments was undertaken to determine the feasibility 
of ultrasonically bonding gold ribbon wire (Lot D) to aluminum pads. It was found that bonds with mean pull strengths of $11.0 \mathrm{gf}$ could be obtain-

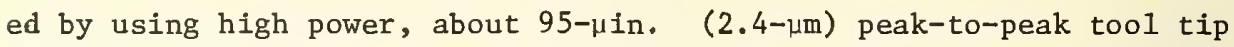
displacement, long time, from 150 and $275 \mathrm{~ms}$, and a bonding force of $35 \mathrm{gf}$. The largest standard deviation was 10.7 percent for a group of ten bonds.

\section{BONDING EQUIPMENT}

The results of the previous section showed that ribbon-wire bonds with high pull strengths and a good appearance could be obtained. These were made on an existing round-wire bonding machine with only slight modifications which are discussed in this section.

\subsection{Wire Clamps}

The major difference between round and ribbon wire ultrasonic bonders is in the wire-feed and wire-clamp mechanisms. Round wire clamps usually open and close in the horizontal plane while ribbon wire clamps usually open and close in the vertical plane in order to grip the wire across its largest dimension. During the course of the program, three companies developed ribbon wire clamps for evaluation. In general, two types of relatively simple modifications were found necessary in order to obtain optimum performance from these clamps. They involved the clamping surfaces and the clamping force on the wire.

The clamping surfaces were lapped plane-parallel and polished to prevent damage to the wire. It was also found advisable to mill away a portion of the clamp that comes closest to the substrate so that bonds could be made in areas on the substrate such as those, for example, near the edge of a package not readily accessible otherwise. These modifications can be performed during manufacture of the clamp.

It was found that ribbon wire clamps should have adjustable clamp pressures so that the pressure can be set at a point where the bonding surfaces of the wire are not work hardened by excessive pressure. One of the clamps examined did not have provision for easily adjusting the clamping pressure. Another had a pneumatic control that proved satisfactory for this purpose. In one case, the clamp linkage had to be 
modified so that the clamping surfaces were far enough apart when open that the wire could move freely between, otherwise unwanted variation in bond loop height was found to result.

\subsection{Tools}

In addition to the experiment previously described where a single tool was used, ultrasonic bonding tools made from different materials and from different vendors were used for making aluminum and gold ribbon wire bonds. Bonding tools from four vendors were used with round and rectangular feed holes in tungsten carbide, titanium carbide, and alloytip tools. Rectangular feed holes proved better than round feed holes in feeding the ribbon wire through the bonding tool, and yielded more uniform tail lengths, loop heights, and less twisting of the wire under the tool. In addition, with a rectangular feed hole, positioning the wire on a small bonding pad is easier to accomplish (see figures 4 and 5).

The surfaces of the bonding tools supplied by a given company as well as on tools obtained from different sources appeared to vary significantly. Some tungsten carbide tools were not homogeneous and had a rough surface finish as shown in figure 12. Another tungsten carbide tool from the same source had a much smoother surface finish as shown in figure 13. Both tools were used for bonding both aluminum and gold ribbon and round wire. Some gold build-up is apparent on the tool shown in figure 12. None appears on the tool shown in figure 13. Some titanium carbide tools that were obtained had pin holes on the bonding surface, and the surface finish was poor (figure 14). The titanium carbide material appeared to be softer and to exhibit more wear than other materials. Alloy-tip bonding tools showed gold buildup on the bonding surface, and some gold particles at the exit of the wire feed-hole due to the roughness of the machined hole as shown in figure 15. During the bonding operation, in many cases, some wire shavings were observed to come off the round or ribbon wire and were found as little curls on the bonding substrate. In addition, the tail length of the ribbon wire varied considerably when using any tool with a roughly-machined feed-hole. For one tool, after polishing the feed- 


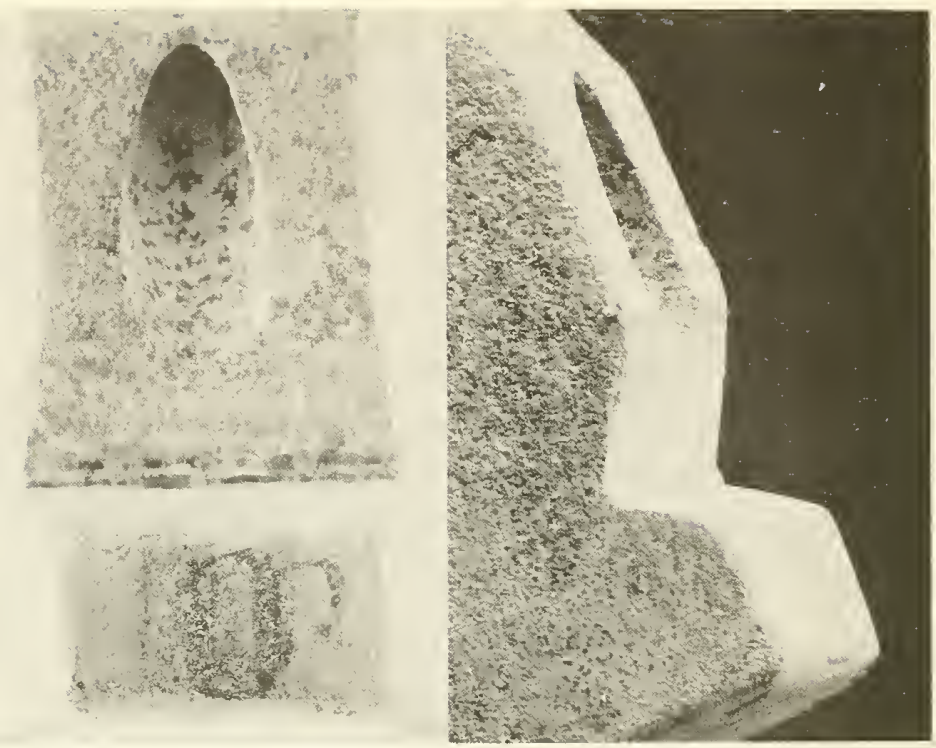

Figure 12: SEM photomicrograph (magnification 240X) of two views of a bonding tool showing rough surface finish.

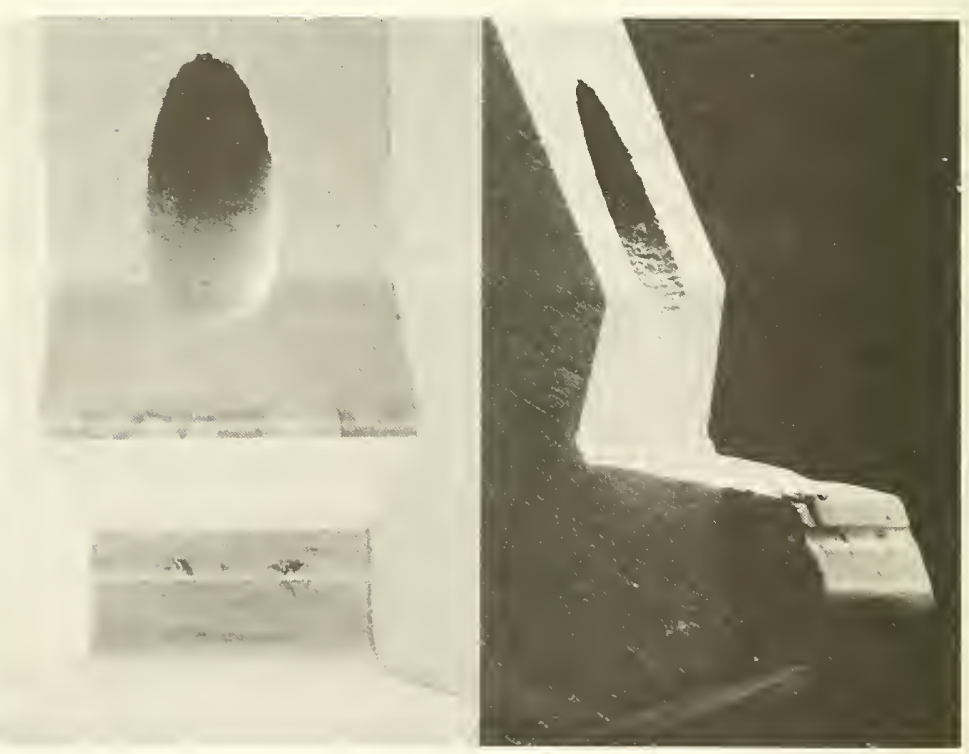

Figure 13: SFM photomicrograph (magnification 200x) of two views of a bonding tool with a relatively smooth surface finish. 


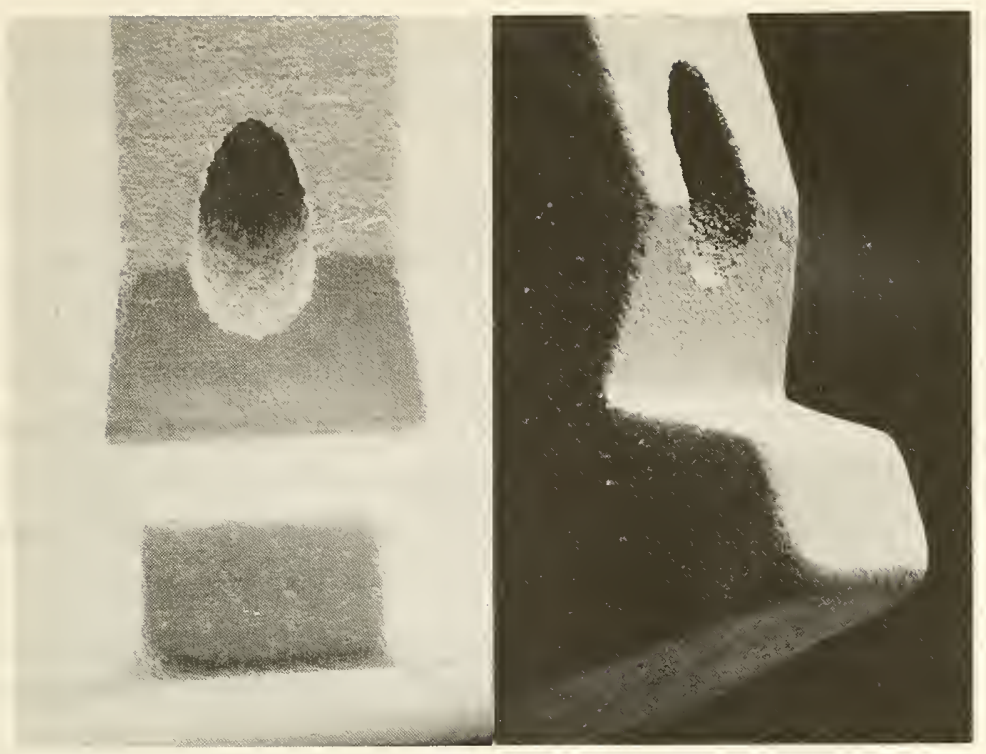

Figure 14: SEM photomicrograph (magnification 190X) of two views of a bonding tool showing pin holes in the surface finish.

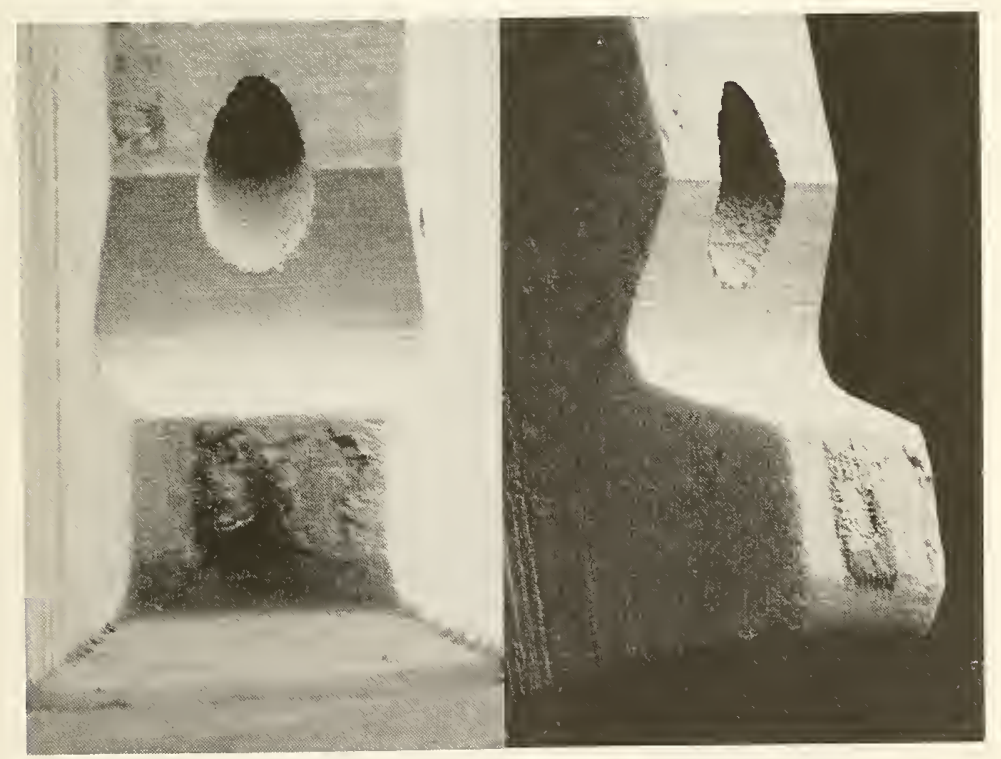

Figure 15: SEM photomicrograph (magnification 200X) of two views of a tungsten carbide bonding tool showing build-up of gold at the wire feed hole. 
hole with a nylon filament and 3-um diamond polishing compound, the tail length variation decreased, and the shaving of the wire was virtually eliminated.

Tools with different footlengths, and front and back radii were examined for use with ribbon wire. In order to achieve optimum reproducible pull strength from ribbon wire bonds it is important to make those bonds with a tool having the correct foot length. In round wire bonding, the tool sinks into the wire as it deforms and increases the length (and area) of contact to include much of the front radius of the tool which is typically $1.5 \mathrm{mils}$. This increases the actual weld length (and area). However, ribbon wire bonds show less deformation than round wire bonds, and the extra length provided by the front radius over the foot length does not contribute to the bond length. A tool with a specified foot length of no less than $4.5 \mathrm{mils}$ has been found to give a satisfactory weld length of approximately 3 mils. Tools with shorter foot lengths tend to produce weaker bonds and bond loops which typically fail in bond pull tests on the second bond. Studies also revealed that the tool heel radius should be no longer than approximately $0.2 \mathrm{mils}$, otherwise the wire cutoff operation may be impaired. 


\section{CONCLUSIONS}

The advantages that are obtained from the use of ribbon wire rather than round wire can be summarized as follows:

1. Bonds of a desired pull strength can be made with ribbon wire over a much greater range of bonding time and power (tool tip displacement) than can comparable round-wire bonds.

2. Ribbon wire bonds can be made one on top of another. This implies that device repair or replacement, as in hybrid devices, can be simply achieved using ribbon wire bonds.

3. Location of ribbon wire bonds can be readily controlled and such bonds can easily be placed side-by-side on a small bonding pad because there is less tendency for ribbon wire to twist or roll out from under the tool tip during bonding than for round wire.

The results presented in this report have demonstrated the basic feasibility and principal advantages of using aluminum ribbon wire for semiconductor microelectronic ultrasonic bonds.

\section{ACKNOWLEDGEMENTS}

This report has benefited considerably from discussions with W. M. Bullis, G. G. Harman, and H. A. Schafft. One of these (GGH) contributed significantly to the project during the first half of the contract period. The work of Mrs. S. A. Davis and Mrs. E. Y. Trager in typing the various manuscripts and L. R. Williams in preparing the illustrations is gratefully acknowledged.

\section{REFERENCES}

References 1, 2, 3, and 5 are contained in quarterly reports of the NBS Semiconductor Technology Program issued in the NBS Technical Note series under the title, Methods of Measurement for Semiconductor Materials, Process Control, and Devices, W. M. Bullis, editor.

1. G. G. Harman, H. K. Kessler, and K. 0. Leedy, NBS Technical Note 488, pp. 24-25 (July 1969).

2. K. 0. Leedy, NBS Technical Note 495, pp. 24-25 (September 1969). 
3. G. G. Harman and H. K. Kessler, NBS Technical Note 527, p. 39 (May 1970).

4. H. A. Schafft, Testing and Fabrication of Wire-Bond Electrical Connections - A Comprehensive Survey, NBS Technical Note 726, pp. 60-68 (September 1972).

5. K. O. Leedy, A. H. Sher, and C. A. Main, NBS Technical Note 743, pp. 27-28 (December 1972). 
FORM NBS-114A (1-71)

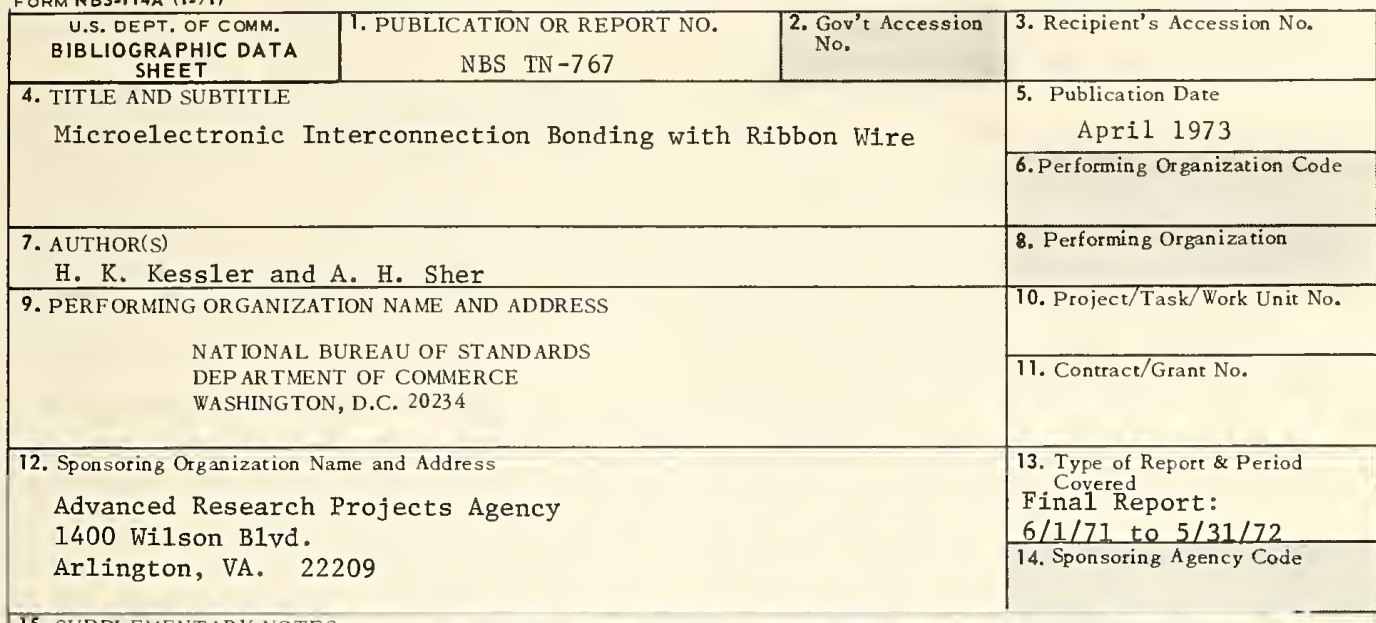

15. SUPPLEMENTARY NOTES

M. Chernoff, ARPA Agent/Project Officer; Directorate of Technology/SYS; Space and Missile System Organization; Air Force Unit Post Office; Los Angeles, CA 90045

16. ABSTRACT (A 200-word or less factual summary of most significant information. If document includes a significant bibliography or literature survey, mention it here.)

The feasibility of using aluminum ribbon wire for ultrasonic bonding of semiconductor microelectronic interconnections was studied, and several advantages over the use of round wire of equivalent cross-sectional area were found. Ribbon wire bonds exhibited little deformation or heel damage, and a greater percentage of bonds of a certain quality (as judged by pull strength and appearance) could be made over much greater ranges of the bonding machine parameters, time and tool tip displacement, using ribbon wire than was possible with round wire. The ease of positioning ribbon wire was indicated by making multiple ribbon wire bonds side-by-side on a 5-mil square pad, or by stacking up to four bonds one on top of another. However, bonding with harder than normal wire, previously thought to offer certain advantages with respect to higher bond tensile strength, yielded inconsistent results.

17. KEY WORDS (Alphabetical order, separated by semicolons)

Aluminum wire; bonding; fabrication (wire bonds); microelectronics; ribbon wire; round wire; testing (wire bond); ultrasonic bonding: wire bond.

18. AVAILABILITY STATEMENT

X] UNLIMITED.

FOR OFFICIAL DISTRIBUTION. DO NOT RELEASE TO NTIS.

\begin{tabular}{|l|c|}
\begin{tabular}{|l|} 
19. SECURITY CLASS \\
(THIS REPORT)
\end{tabular} & 21. NO. OF PAGES \\
UNCL ASSIFIED & 31 \\
\hline 20. SECURITY CLASS & 22. Price \\
(THIS PAGE) & .50 Domestic postpaid \\
UNCL ASSIFIED & .35 G.P.O. Bookstore \\
\hline
\end{tabular}




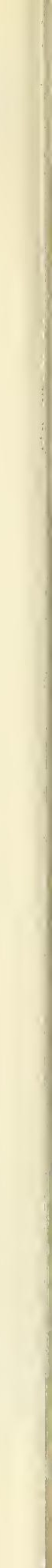




\section{NBS TECHNICAL PUBLICATIONS}

\section{PERIODICALS}

JOURNAL OF RESEARCH reports National Bureau of Standards research and development in physics, mathematics, and chemistry. Comprehensive scientific papers give complete details of the work, including laboratory data, experimental procedures, and theoretical and mathematical analyses. Illustrated with photographs, drawings, and charts. Includes listings of other NBS papers as issued.

Published in two sections, available separately:

\section{- Physics and Chemistry (Section A)}

Papers of interest primarily to scientists working in these fields. This section covers a broad range of physical and chemical research, with major emphasis on standards of physical measurement, fundamental constants, and properties of matter. Issued six times a year. Annual subscription: Domestic, $\$ 17.00$; Foreign, \$21.25.

\section{- Mathematical Sciences (Section B)}

Studies and compilations designed mainly for the mathematician and theoretical physicist. Topics in mathematical statistics, theory of experiment design, numerical analysis, theoretical physics and chemistry, logical design and programming of computers and computer systems. Short numerical tables. Issued quarterly. Annual subscription: Domestic, $\$ 9.00$; Foreign, $\$ 11.25$.

\section{TECHNICAL NEWS BULLETIN}

The best single source of information concerning the Bureau's measurement, research, developmental, cooperative, and publication activities, this monthly publication is designed for the industry-oriented individual whose daily work involves intimate contact with science and technology-for engineers, chemists, physicists, research managers, product-development managers, and company executives. Includes listing of all NBS papers as issued. Annual subscription: Domestic, \$6.50; Foreign, \$8.25.

\section{NONPERIODICALS}

Applied Mathematics Series. Mathematical tables, manuals, and studies.

Building Science Series. Research results, test methods, and performance criteria of building materials, components, systems, and structures.

Handbooks. Recommended codes of engineering and industrial practice (including safety codes) developed in cooperation with interested industries, professional organizations, and regulatory bodies.

Special Publications. Proceedings of NBS conferences, bibliographies, annual reports, wall charts, pamphlets, etc.

Monographs. Major contributions to the technical literature on various subjects related to the Bureau's scientific and technical activities.

National Standard Reference Data Series. NSRDS provides quantitative data on the physical and chemical properties of materials, compiled from the world's literature and critically evaluated.

Product Standards. Provide requirements for sizes, types, quality, and methods for testing various industrial products. These standards are developed cooperatively with interested Government and industry groups and provide the basis for common understanding of product characteristics for both buyers and sellers. Their use is voluntary.

Technical Notes. This series consists of communications and reports covering both other-agency and NBS-sponsored work) of limited or transitory interest.

Federal Information Processing Standards Publications. This series is the official publication within the Federal Government for information on standards adopted and promulgated under the Public Law 89-306, and Bureau of the Budget Circular A-86 entitled, Standardization of Data Elements and Codes in Data Systems.

Consumer Information Series. Practical information, based on NBS research and experience, covering areas of interest to the consumer. Easily understandable language and illustrations provide useful background knowledge for shopping in today's technological marketplace.

\section{BIBLIOGRAPHIC SUBSCRIPTION SERVICES}

The following current-awareness and literature-survey bibliographies are issued periodically by the Bureau :

Cryogenic Data Center Current Awareness Service (Publications and Reports of Interest in Cryog̀enics). A literature survey issued weekly. Annual subscription: Domestic, $\$ 20.00$; foreign, $\$ 25.00$.

Liquefied Natural Gas. A literature survey issued quarterly. Annual subscription: $\$ 20.00$.

Superconducting Devices and Materials. A literature survey issued quarterly. Annual subscription: $\$ 20.00$. Send subscription orders and remittances for the preceding bibliographic services to the U.S. Department of Commerce, National Technical Information Service, Springfield, Va. 22151.

Electromagnetic Metrology Current Awareness Service (Abstracts of Selected Articles on Measurement Techniques and Standards of Electromagnetic Quantities from D-C to Millimeter-Wave Frequencies). Issued monthly. Annual subscription: $\$ 100.00$ (Special rates for multi-subscriptions). Send subscription order and remittance to the Electromagnetic Metrology Information Center, Electromagnetics Division, National Bureau of Standards, Boulder, Colo. 80302.

Order NBS publications (except Bibliographic Subscription Services) from: Superintendent of Documents, Government Printing Office, Washington, D.C. 20402. 
U.S. DEPARTMENT OF COMMERCE

National Bureau of Standards

Washington, D.C. 20234

POSTAGE AND FEES PAID U.S. DEPARTMENT OF COMMERCE 215

215

DFFICIAL BUSINESS

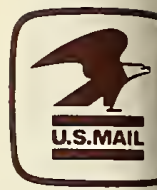

Penalty for Privata Use. \$3DD 